\title{
И.В. Жолтовский - ученик Академии художеств, педагог Строгановского художественно-промышленного училища
}

\author{
Л.И.Иванова-Веэн, МАРХИ, Москва
}

Музей истории московской архитектурной школы при МАРХИ придает большое значение периоду учёбы и педагогической деятельности мастеров архитектуры, среди которых особое место занимает Иван Владиславович Жолтовский. В 1940-х годах он был художественным руководителем Московского архитектурного института, в связи с чем для нас важным является изучение истоков формирования его педагогического мастерства. На основе собранных Музеем МАРХИ материалов были проведены юбилейные выставки к 125- и 150-летию со дня рождения мастера, на которых были представлены свидетельства его педагогической деятельности.

В данной публикации рассматривается период обучения Ивана Жолтовского в Императорской Академии художеств - Высшем художественном училище (1887-1898). Ранее на основе его личного дела в Академии исследователь 0.С. Шурыгина достаточно детально раскрыла период обучения. Автором публикации выявлены новые данные биографии Жолтовского этого периода: «Свидетельство о прописке», с которым он поступал в Академию художеств, фотопортрет и учебные работы. Особый интерес представляет впервые публикуемый здесь проект церкви, который, по мнению автора публикации, был удостоен Большой серебряной медали (1893).

В статье анализируется период преподавания И.В. Жолтовским художественных предметов в Строгановском художественно-промышленном училище в 1900-1904 годах. На основе сведений личного дела преподавателя Училища (РГАЛИ) установлено, что он был «преподавателем художественных предметов» - рисования и композиции. Впервые публикуется фотография Жолтовского в мастерской (1902). На сегодняшний день это наиболее полная информация о его учебе и преподавании в дореволюционный период.

Ключевые слова: И.В. Жолтовский, архитектурное образование, ВХУ ИАХ, Строгановское училище.

\section{I.V. Zholtovsky - Student of the Academy of Arts, Teacher of the Stroganov Art and Industrial School \\ L.I.Ivanova-Veen, MArkhI, Moscow}

The Museum of the History of the Moscow School of Architecture at the MARKHI attaches great importance to the period of study and pedagogical activity of the masters of architecture, among whom a special place is occupied by Ivan Vladislavovich Zholtovsky. In the 1940s, he was the artistic director of the Moscow Architectural Institute, in connection with which it is important for us to study the origins of the formation of his pedagogical skills. On the basis of the materials collected by the MARKHI Museum, commemorative exhibitions were held to mark the 125th and 150th anniversary of the master's birth, where evidence of his teaching activities was presented.

This publication examines the period of Ivan Zholtovsky's studies at the Imperial Academy of Arts-the Higher Art School (1887-1898). Earlier, on the basis of his personal file at the Academy, researcher 0 . S. Shurygina revealed the period of training in sufficient detail.The author of the publication revealed new data from Zholtovsky's biography of this period: the "Certificate of registration", with which he entered the Academy of Arts, a photo portrait and educational works. of particular interest is the project of the church published here for the first time, which, according to the author of the publication, was awarded a Large Silver Medal (1893).

The article analyzes the period of teaching art subjects by N.V. Zholtovsky at the Stroganov Art and Industrial School in 1900-1904. On the basis of the personal file of the teacher of the School (RGALI), it was established that he was a "teacher of art subjects" - drawing and composition.First published photo of Zholtovsky in the workshop 1902. To date, this is the most complete information about his studies and teaching in the pre-revolutionary period.

Keywords: I.V. Zholtovsky, architectural education, Higher Art School of Imperial Academy of Arts, Stroganov School.

Архитектурное наследие выдающегося зодчего Ивана Владиславовича Жолтовского (1867-1959) достаточно хорошо изучено в трудах Г.Д. Ощепкова, Н.П. Былинкина, С.О. ХанМагомедова [1-3], а также ряда современных исследователей. Период обучения Жолтовского в Императорской Академии художеств (ИАХ) и его преподавательской деятельности в Строгановском училище рассмотрен Н.П. Сукояном и О.С. Шурыгиной [4; 5]. Важно отметить, что Ощепков опубликовал статью о Жолтовском при жизни мастера, а Сукоян был одним из ближайших его учеников и добавил факты из творческой биографии зодчего.

Основная часть творческого наследия мастера поступила в ГНИМА им. А.В. Щусева после смерти зодчего, дополнена материалами Школы-мастерской Жолтовского из Моспроекта и каталогизирована [6, с. 74]. В данной публикации приводятся ране неизвестные свидетельства периода учёбы Жолтовского в Академии художеств и начала его педагогической деятельности в Строгановском училище. 
Преподавательская деятельность мастера стала изучаться под руководством автора статьи с 1990-х годов в созданном Музее МАРХИ. Сбор материалов по теме педагогического наследия И.В. Жолтовского начался во время подготовки выставки 1992 года, посвящённой 125-летию мастера. Учениками зодчего были переданы в дар различные материалы: чертежи, документы, фотографии. Важную часть даров составили учебные проекты, выполненные студентами Московского архитектурного института (МАИ) 1938-1948 годов - периода, когда Жолтовский был его художественным руководителем. Экспонаты были выставлены в Музее МАРХИ, и состоялся вечер памяти о педагоге.

В рамках подготовки 150-летнего юбилея зодчего (2017) посещались квартира Жолтовского на улице Станкевича в Москве, а также его дача в Дарьино Московской области. Загородный деревянный дом к тому времени уже был разобран. Часть вещей хранилась в соседнем доме - мебель, подарки учеников и фотографии. Тогда же некоторые личные вещи и фотографии поступили в фонд Музея МАРХИ. В 2017 году к 150-летию мастера в Галерее ВХУТЕМАС была организована большая выставка, на которой экспонировались вновь поступившие материалы. В данной статье часть переданных фотографий, представленных на юбилейной выставке, публикуется впервые.

Теперь обратимся к ранним годам жизни мастера. Он родился в 1867 году в Пинском уезде Минской губернии. Как сообщает Шурыгина, в 1878-1879 годы он учился в Пинском реальном училище, среднее образование получил в 1884-1886 годы в Астраханском реальном училище. Исследователь Шурыгина, ссылаясь на данные краеведов, отмечает невысокий уровень оценок Жолтовского в Астраханском училище по всем предметам за исключением черчения - на «отлично» [5, с. 172]. Следующий год он провёл в Риге, где, возможно, учился в местном реальном училище [5, с. 171]. Обнаружен самый ранний из опубликованных документ - «Свидетельство о приписке к призывному участку города Риги» (рис. 1), где сказано, что Жолтовский окончил Астраханское реальное училище 14 июня 1986 года. Обратим внимание, что это Свидетельство обнаружено в личном деле педагога Строгановского училища. Судя по виду, документ, некогда сложенный в четыре раза, с оборванными краями, путешествовал с хозяином до лета 1900 года. Сегодня нам неизвестно, кто был наставником Жолтовского в Астрахани и Риге, кто его подвиг поступать в Академию.

В 1887 году Жолтовский в возрасте двадцати лет поступил в Императорскую Академию художеств. 0 периоде обучения в Академии мы знаем из личного дела учащегося ИАХ ${ }^{1}$, которое достаточно подробно описано Шурыгиной [5, с. 170] и где она публикует фотографию с подписью «Дворянин Иван Владиславович Жолтовский» (рис. 2). Здесь публикуется еще одна фотография, скорее всего относящаяся к более раннему периоду, из собрания Музея МАРХИ (рис. 2).

Как писал Сукоян о наставниках Жолтовского в Академии: «Из учителей он более всего вспоминал профессоров Гедике (архитектура) и Шрейбера (рисунок)» [4, с. 307].
Удалось выявить ученические работы Жолтовского периодаучёбы в Академии, которыепредставляют собой акварельные зарисовки фрагмента камина (1887) и фасад алтаря (1888) (рис. 3). Они вошли в запись каталога ГНИМА, но никогда не публиковались [6, с. 74]

До недавнего времени основным источником сведений об образовании Жолтовского был справочник С.Н. Кондакова, где сообщается, что он получил две серебряные медали в 1890 году, еще одну - в 1893-ем. Личное дело подтверждает только получение одной малой медали в 1890 году. В октябре 1893 года

${ }^{1}$ РГИА. Ф. 789.0 0п. 11. 1887 г. Д. 115.

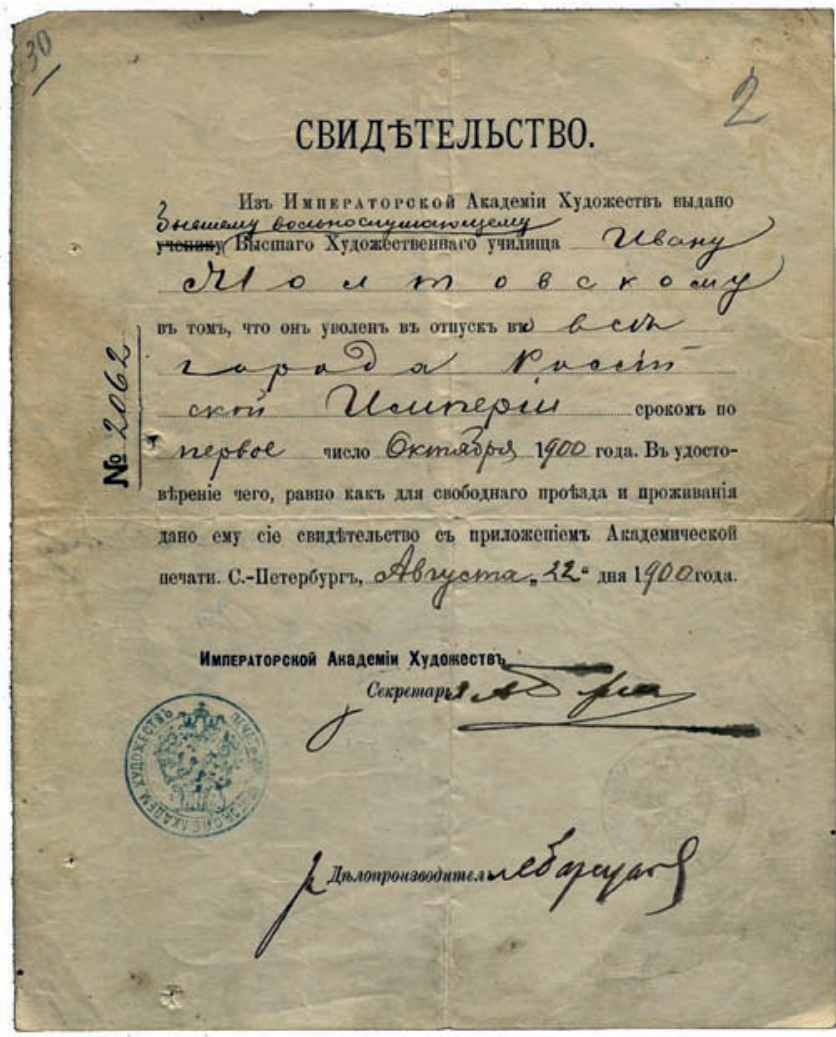

Рис. 1. Свидетельство о приписке к призывному участку города Риги (источник: РГАЛИ. Ф.677. Оп. 1. Д. 3147)

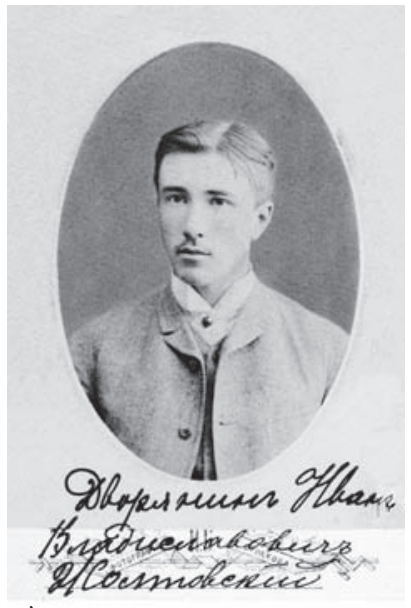

a)

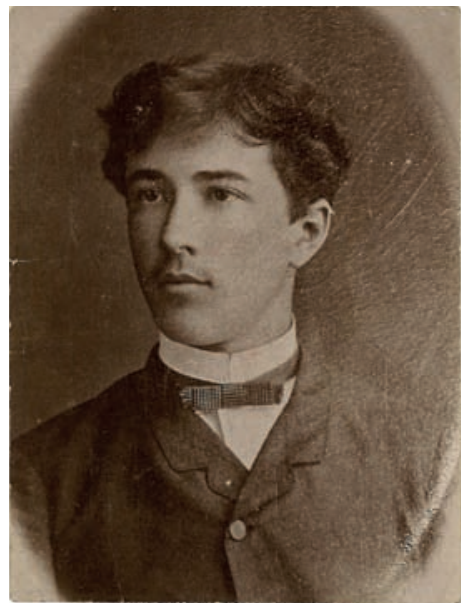

б)

Рис. 2. Иван Владиславович Жолтовский: а) (источник: [5]); б) публикуется впервые (источник: музей МАРХИ) 
он сделал проект церкви, удостоенный Большой серебряной медали, что подтверждается личным делом². В частном собрании наследников А.В. Щусева удалось найти проект церкви в русском стиле (рис. 4). На чертеже изображены фасад со стороны алтаря и план церкви - в правом верхнем углу. Проект выполнен на высоком художественном уровне. Штамп в левом нижнем углу «ИАХ. худож. экзам. 22 октября 1893 г.»³ даёт нам основание утверждать, что это действительно тот самый проект,

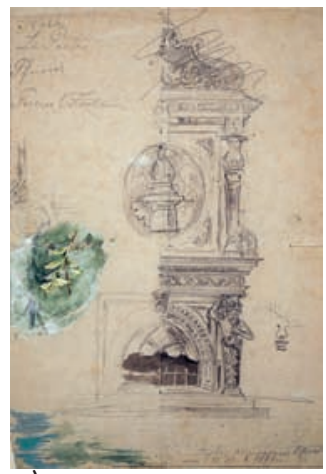

a)

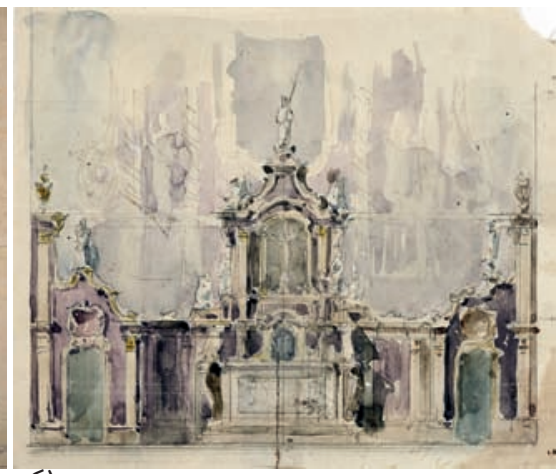

б)

Рис. 3. Работы Жолтовского периода учёбы в Академии. (источник: ГнИМА им. А.В. Щусева): а) фрагмент камина (акварель, 1887) и б) фасад алтаря (акварель, 1888). Публикуются впервые

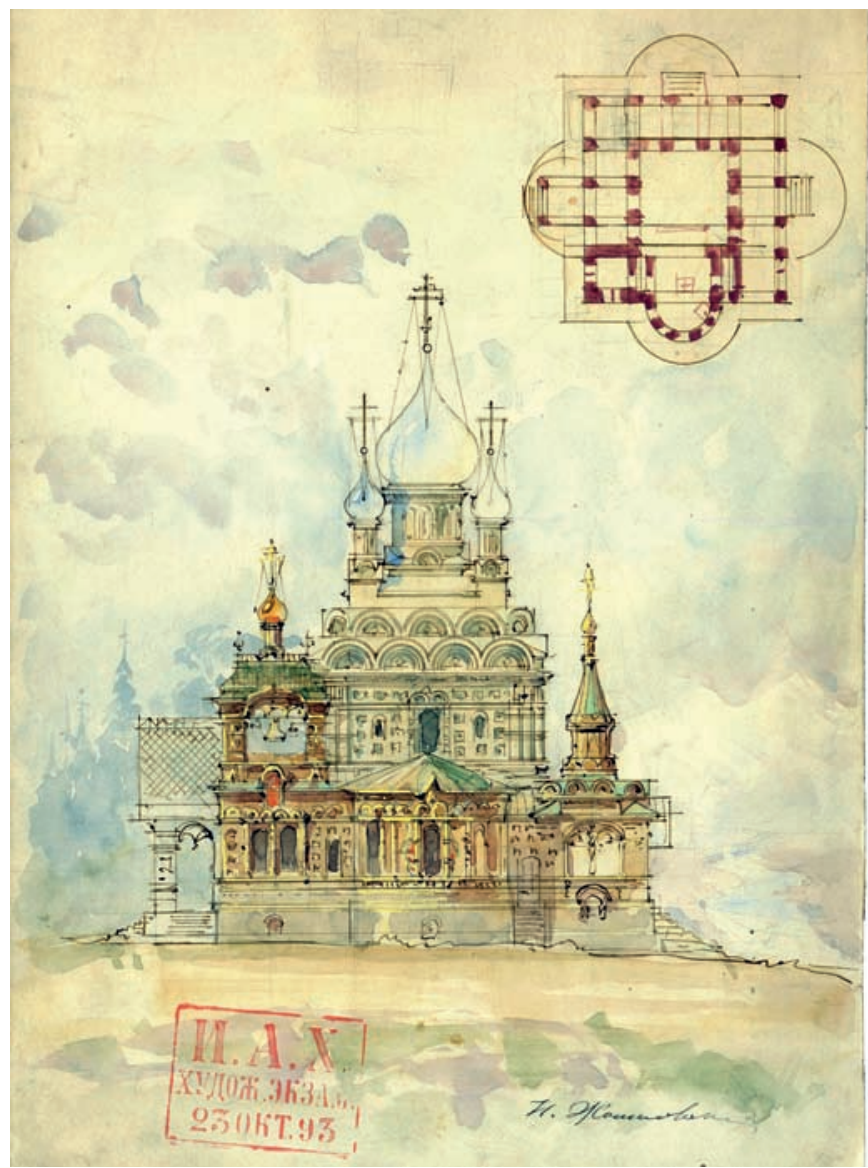

Pис. 4. Проект церкви в русском стиле, удостоенный Большой серебряной медали в 1983 году (источник: частное собрание наследников А.В. Щусева). Публикуется впервые за который Жолтовский получил Большую серебряную медаль. Следует отметить, что именно в этом году произошла реформа художественного образования, связанная с новым Уставом, - из ИАХ было выделено Высшее художественное училище (ВХУ).

Успешно занимаясь проектированием, Жолтовский отставал по рисованию и наукам, он дважды отчислялся из Академии 4 . Сукоян и Ощепков объясняют это загруженностью на постройках в Петербурге. Он работал помощником у ряда архитекторов-практиков - Марфельда, Степанова и Гаугера, и участвовал в конкурсах.

Для продолжения занятий он стал в 1897 году вольнослушателем ВХУ, был принят в мастерскую профессора А.0 Томишко ${ }^{5}$ «ввиду его особых художественных способностей» ${ }^{6} .2$ ноября 1898 года Жолтовским был выполнен выпускной проект «Народный дом, включающий в себя столовую, театр и библиотеку» $[1, \text { с. 6 }]^{7}$. Кондаков сообщает, что за эту работу он был удостоен «звания художника-архитектора» [7, с. 323]. Это повторяют Ощепков, Былинкин и др. На самом деле Жолтовский окончил обучение в ВХУ ИАХ как вольнослушатель, поскольку не сдал ряд предметов по курсу наук.

С ноября 1898 года до августа 1900-го никакой информации об И.В. Жолтовском нет (за исключением заключения брака с Амалией Константиновной (маровской).

Обучение в BХУ ИАХ является принципиально важным для формирования Жолтовского как архитектора, сделавшим его убеждённым приверженцем классической архитектуры и академической системы образования. Несмотря на неуспеваемость по отдельным предметам, сверстники по Академии очень ценили Жолтовского как знатока архитектуры. Интересным фактом, по воспоминаниям А.В. Щусева, было то, что в период учёбы в Академии Жолтовский проводил экскурсии с однокашниками: «...мы, новички ...слушали его беседы об архитектуре с большим увлечением..., в белые петербургские ночи мы часто простаивали, беседуя перед фасадами дворцов и памятников до самого утра»» [4, с. 308]. .Из этих воспоминаний видно, что уже в период учёбы в Академии демонстрировал свои преподавательские способности и устремления ${ }^{8}$.

${ }^{2}$ РГИА. Ф. 789. 0п. 11. 1887 г. Д. 115. Л. 45.

Эти ученические работы демонстрировались впервые на выставке к 150-летию мастера в Галерее ВХУТЕМАС в 2017 году.

${ }^{4}$ Отчислен в мае 1891 года как «не сдавший наук» (восстановился в апреле 1892 года); затем он был повторно отчислен в 1897 году, а в 1889-ом Жолтовский остался на второй год (РГИА. Ф. 789. 0п. 11. 1887 г. Д. 115. Л. 45].

${ }^{5}$ Томишко Антоний Осипович (Иосифович) (1851-1900) - архитектор. у Г.Д. Ощепкова ошибочно значится Л.И. Томишко [1, с. 6]. Томишко учился в УЖВ3, с 1870 года в ИАХ, в 1873 году получил Малую золотую медаль, в 1875-ом получил звание классного художника I степени, был отправлен пенсионером за границу. Академик и преподаватель ИАХ с 1879 года, с 1888 года профессор, с 1894-го руководитель мастерской, ректор ВХУ в 1897-1898 годы.

${ }^{6}$ РГИА. Ф. 789. 0п. 11. 1887 г. Д. 115. Л. 56.

7 Фотография этого проекта была выявлена И.Е. Печенкиным и О.С. Шурыгиной в ГАРФе.

${ }^{8}$ Как мне рассказывали ученики Жолтовского, он проводил беседы на своей квартире на ул. Станкевича со студентами МАИ и архитекторами Школы-мастерской (1940-1950-е годы). 
В середине 1900 года Жолтовский начал новый этап своей жизни - приступил к педагогической деятельности в Строгановском училище. Как сообщает Ощепков, Жолтовский поехал на работу в Иркутск, но «во время остановки в Москве он получил приглашение преподавать в Строгановском художественно-промышленном училище» $[1$, c. 6]. В это время директором училища был Н.В. Глоба (выпускник ИАХ 1887 года). Из отчёта Училища за 1900 год стало известно, что Жолтовский был приглашен преподавать композицию на место В.В. Попова, скончавшегося в октябре 1899 года9 . Его прошение о приёме штатным преподавателем относится к 29 сентября 1900 года. Оно находится в личном деле «0б определении на должность преподавателя рисования художника Ивана Жолтовского» ${ }^{10}$. В этом деле находится свидетельство (22 августа) из ИАХ как уволенного в отпуск (до 1 октября 1900 года) «бывшему вольнослушающему» ВХУ1 (рис. 5). 7 декабря 1900 года он получил свидетельство как «прошедший курс архитектурного отделения» справом преподавания рисования в среднихучебных заведениях [5, с. 173]. Жолтовский был принят на должность преподавателя 11 декабря 1900 года ${ }^{12}$, «определён на службу в штат преподавателем в Строгановское училище» по приказу Министерства финансов от 4 января 1901 года ${ }^{13}$.

В это время в Строгановке преподавали известные архитекторы: Ф.Ф. Богданович, Л.М. Браиловский, С.У. Соловьев, С.В. Ноаковский - выпускники Академии художеств, а также Л.Н. Кекушев, Ф.0. Шехтель. В личном деле Жолтовского находятся документы 1902 года о разрешении «беспрепятственного срисовывания памятников Москвы, русской старины в пределах Кремля и Кремлёвских соборов» ${ }^{14}$. Это свидетельствует о большом интересе к истории русской архитектуры. В это время он вёл интенсивную творческую деятельность, брал заказы. Его увлекала классическая тема. У него был ряд заказов, в том числе проекты гостиницы «Метрополь», Дома Скакового общества и др. К 1902 году относится фотография Жолтовского в мастерской (рис. 6) из фондов Музея МАРХИ. В личном деле находится серия прошений Жолтовского на заграничный отпуск ${ }^{15}$. В аттестате, составленном Глобой, перечислены их даты: с 1 мая по 1 сентября 1902 года, с 1 по 15 августа 1903 года, с 19 декабря 1903 года по 7 января 1904 года ${ }^{16}$.

В 1904 году произошёл конфликт Жолтовского с директором училища. Как отмечает Сукоян, Жолтовский не выдержал «ужасающего режима», насаждаемого директором [4, с. 308]. 8 ноября 1904 года Жолтовским было подано прошение об увольнении суказанием причины: «Имея в виду выраженные Вами преподавателям на последнем заседании по вопросам композиции “недоверие". ...», с подписью: «Преподаватель Архитектор-художник Иван Жолтовский» ${ }^{17}$. Его прошение было подписано Глобой 12 декабря

${ }_{9}^{9}$ РГАЛИ. Ф. 677. 0п. 2. Д. 37. Л. 25 об.

${ }^{10}$ РГАЛИ. Ф. 677. 0п. 1. Д. 3147. Л. 3.

${ }^{11}$ Там же, л. 2.

12 Там же, л. 9.

13 Там же, л. 14.

${ }^{14}$ Там же, л. 17-21.

${ }^{15}$ Там же, л. 25-29.

${ }^{16}$ Там же, л. 53, об.
1904 года ${ }^{18}$. Последний документ личного дела - Формулярный список от 13 января 1905 года, в котором он значится как «преподаватель художественных предметов» ${ }^{19}$. Выше он упоминается как преподаватель «рисования» и «композиции».

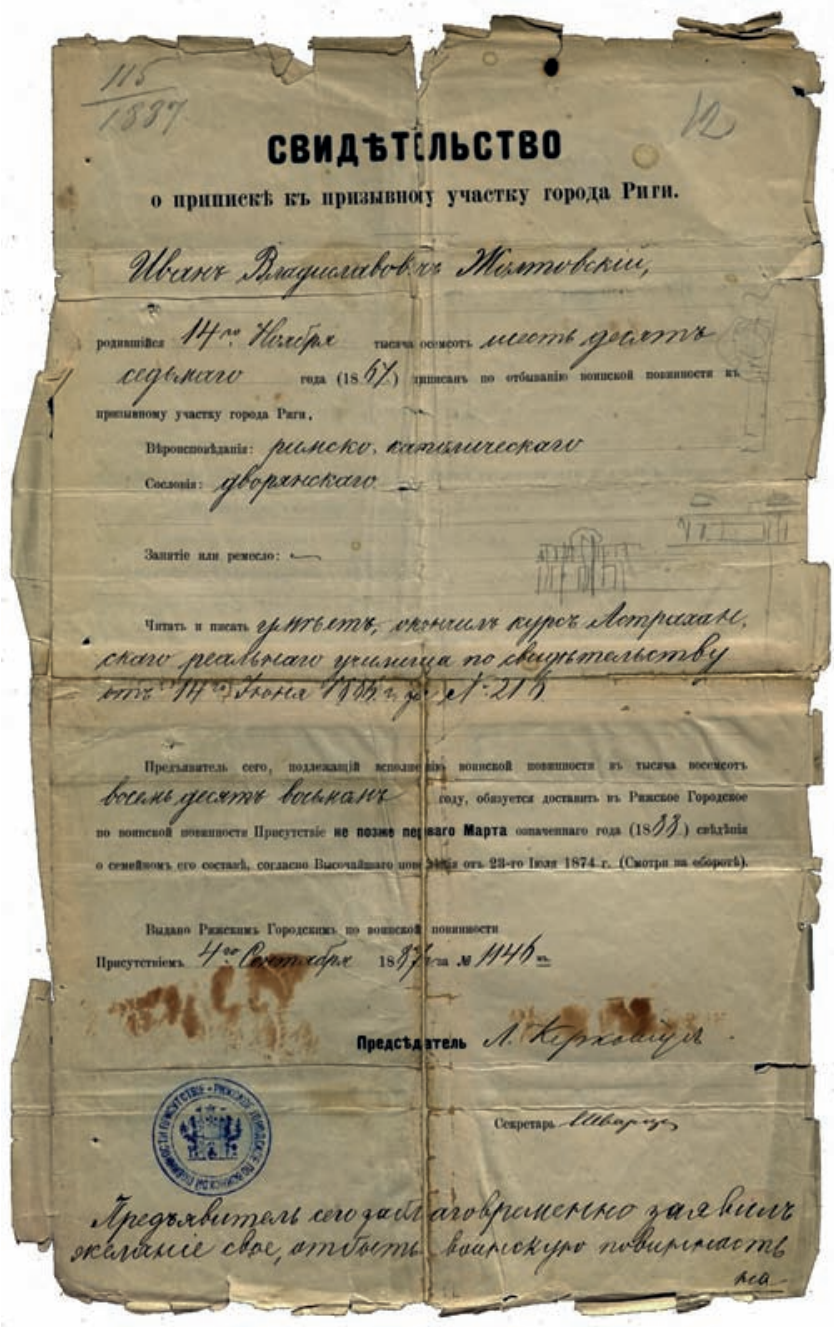

Рис. 5. Свидетельство о приписке к призывному участку города Риги (источник: РГАЛИ. Ф.677. Оп. 1. Д. 3147). Публикуется впервые

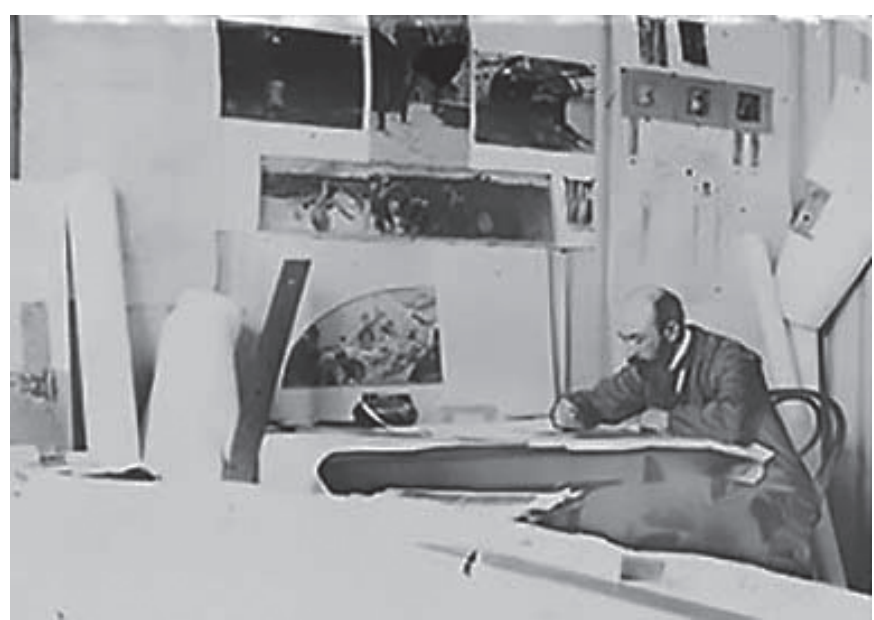

Рис. б. И.В. Жолтовский в мастерской. Фото 1902 года (источник: фонды Музея МАРХИ). Публикуется впервые 
Среди его учеников в училище - в будущем известный художник С.В. Герасимов (учился в 1901-1907 годы). И.И. Нивинский, выпускник, преподаватель Строгановского училища, считал Жолтовского «учителем и наставником в искусстве» [4, с. 308].

В 1909 году члены Академии художеств предложили собранию Академии удостоить Жолтовского почётного звания академика архитектуры [5, с. 174].Таким образом это почетное звание стало подтверждением его высокого профессионального уровня.

Преподавательская деятельность Жолтовского была прервана почти на 13 лет. В 1917 г. ученики Училища живописи, ваяния и зодчества пригласили И.В. Жолтовского в качестве преподавателя на Архитектурное отделение; с 1918 г. он руководил архитектурной мастерской в Свободных Гсударственных художественных мастерских; с 1920 по 1923 гг. - профессор Архфака ВХУТЕМАСа. Это был яркий этап его педагогической деятельности. Он будет освещён автором в следующей статье.

\section{Литература}

1. И.В. Жолтовский. Проекты и постройки. / Сост. Ощепков Г.Д. - М. : Государственное издательство литературы по строительству и архитектуре, 1955. - 160 с.

2. Былинкин, Н.П. Иван Владиславович Жолтовский (18671959) // Мастера советской архитектуры об архитектуре : в 2-х томах / М.Г. Бархин (ред.). - М. : Искусство, 1975. - С. 23-55.

3. Хан-Магомедов, С.О. Иван Жолтовский / С.0. ХанМагомедов. - М. : РИП-холдинг, 2010. - 352 с. ISBN 978-591566-036-5

4. Сукоян, Н.П. Иван Владиславович Жолтовский. Творческая биография / Н.П. Сукоян // Архитектурное наследство. - 2005. - Вып. 46. - С. 307-324.

5. Шурыгина, О.С. Новые данные о И.В. Жолтовском (к 150-летию со дня рождения архитектора) / 0.С. Шурыгина // Архитектурное наследство. - 2017. - Вып. 67. - С. 170-184.

6. Архитектор Иван Владиславович Жолтовский (1867-1959) : Архит. мастерская-школа И. В. Жолтовского (1945-1959) : Каталог-путеводитель по фондам музея / Гос. н.-и. музей архитектуры им. А. В. Щусева / Сост. О. М. Зюскевич, Н. И. Филюкова. - М. : ЦНТИ по гражд. стр-ву и архитектуре, 1985. - 109 с.

7. Список русских художников. К юбилейному справочнику ИАХ /Автор-сост. Кондаков С.Н. - СПб, 1914. - 323 с.
8. Печёнкин И.Е, Шурыгина О.С. Иван Жолтовский и Императорская Академия художеств / И.Е. Печёнкин, О.С. Шурыгина // Наука, образование и экспериментальное проектирование : Тезисы докладов научной конференции. Москва, МАРХИ, сентябрь 2018 г. - М. : МАРХИ, 2018. - С. 115-116.

\section{References}

1. I.V. Zholtovskii. Proekty i postroiki [Projects and buildings] / Sost. G.D. Oshchepkov (comp). Moscow, State publishing house of literature on construction and architecture,1955, 160 p. (In Russ.)

2. Bylinkin N.P. Ivan Vladislavovich Zholtovskii (18671959). In: Mastera sovetskoi arkhitektury ob arkhitekture [Masters of Soviet architecture about architecture], M.G. Barhin (ed.). Moscow, Isskustvo Publ., 1975, pp. 23-55. (In Russ.)

3. Khan-Magomedov S.0. Ivan Zholtovskii. Moscow, RIPkholding Publ., 2010, 352 p. ISBN 978-5-91566-036-5 (In Russ.)

4. Sukoyan N.P. Ivan Vladislavovich Zholtovskii. Tvorcheskaya biografiya [Ivan Vladislavovich Zholtovskii. Creative biography]. In: Arkhitekturnoe nasledstvo [Architectural heritage], 2005, Iss. 46, pp. 307-324. (In Russ.)

5. Shurygina 0.S. Novye dannye o I.V. Zholtovskom (k 150-letiyu so dnya rozhdeniya arkhitektora) [New data about I.V. Zholtovsky (to the 150th anniversary of the birth of the architect)]. In: Arkhitekturnoe nasledstvo [Architectural heritage], 2017, Iss. 67, pp. 170-184. (In Russ., abstr. in Engl.)

6. Arkhitektor Ivan Vladislavovich Zholtovskii (1867-1959) : Arkhit. masterskaya-shkola I.V. Zholtovskogo (1945-1959) : Katalog-putevoditel' po fondam muzeya [Architect Ivan Vladislavovich Zholtovsky (1867-1959): Architect. workshopschool of I.V. Zholtovsky (1945-1959): Catalog-guide to the funds of the museum], 0.M. Zyuskevich, N.I. Filyukova (comp.). Moscow, TsNTI civil. building and architecture Publ., 1985, 109 p.

7. Kondakov S.N. (auth.and comp.) Spisok russkikh khudozhnikov. K yubileinomu spravochniku IAKh [List of Russian artists. To the jubilee reference book IAH]. St. Petersburg, 1914, 323 p. (In Russ.)

8. Pechenkin I.E, Shurygina 0.S. IvanZholtovskii imperatorskaya Akademiya khudozhestv [Ivan Zholtovsky and the Imperial Academy of Arts] In: Nauka, obrazovanie $i$ eksperimental'noe proektirovanie: Tezisy dokladov [Science, education and experimental design: Abstracts of the scientific conference], Moscow, MARKHI, September, 2018. Moscow, MARKHI Publ., 2018, pp. 115-116.

Иванова-Веэн Лариса Ивановна (Москва). Кандидат архитектуры, доцент. Директор Музея истории московской архитектурной школы при Московском архитектурном институте (107031, Москва, улица Рождественка, дом 11/4. МАРХИ). Эл.почта: museum@markhi.ru.

Ivanova-Veen Larisa I. (Moscow). Candidate of Architecture, Associate Professor. Director of the Museum of History of the Moscow School of Architecture at the Moscow Institute of Architecture (11/4 Rozhdestvenka st, Moscow, 107031. MARKHI). E-mail:museum@markhi.ru.

\footnotetext{
${ }_{17}$ РГАЛИ. Ф. 677. 0п. 1. Д. 3147. Л. 52.

18 Там же, л. 51.

${ }^{19}$ Там же, л. 59.
} 